\title{
O DESAFIO DE EDITAR PESSOA ENTREVISTA COM JERÔNIMO PIZARRO
}

\author{
Gustavo Bragança é doutorando em Estudos Literários - Literatura Brasileira do Departamento de Letras da PUC-Rio e realiza \\ estágio de doutorado no exterior (Bolsa PDEE - Proc. $n^{\circ}$ 6739-10-5) no Centro de Estudos Comparatistas da Faculdade de Letras da \\ Universidade de Lisboa. \\ E-mail: gustavombraganca@yahoo.com.br
}

\section{Resumo:}

Esta entrevista com o pesquisador e editor Jerônimo Pizarro tem como tema questões metodológicas e éticas relacionadas ao trabalho de edição da obra de Fernando Pessoa.

\begin{abstract}
:
This interview with researcher and editor Jerônimo Pizarro has as its theme methodological and ethical issues related to the task of editing the works of Fernando Pessoa.
\end{abstract}

Pessoa existe nos papéis. À medida que vão desaparecendo os homens que o conheceram e dele deram testemunho (e cujos evangelhos nem sempre são fundamento de fé, sobretudo se interpretativos), mais evidente se torna que só resta uma forma de até ele chegar: lê-lo.

Ler o que escreveu. Mas ler o que efectivamente escreveu.

Ivo Castro

\section{1) Apresentação}

Por maior que seja o reconhecimento que tenha alcançado Fernando Pessoa desde a sua morte em 1935, Pessoa ainda é aquele autor por conhecer, evocando o título do livro organizado por Teresa Rita Lopes, um dentre os relevantes projetos editoriais que, nas últimas décadas, contribuem para trazer à tona a obra de um escritor ainda parcialmente desconhecido. O desconhecimento aqui referido aplica-se, sobretudo, não à fama de Pessoa - já bem estabelecida - e também não propriamente ao fato de que aquilo que já foi editado ainda está longe de concluir a tarefa de cobrir a vastidão dos textos e fragmentos póstumos guardados pelo escritor e nunca publicados, mas, antes, refere-se à constatação de que o caráter póstumo de Pessoa (e o que isto pode conferir à edição e à recepção de seus escritos) não ser algo suficientemente divulgado nem mesmo debatido, sobretudo, parece-me, fora de Portugal.

Muitos leitores do escritor português sabem pouco ou nada sobre o intensivo trabalho dos investigadores para extrair - de manuscritos de difícil leitura e de 
datiloscritos repletos de lacunas e anotações rabiscadas - os textos posteriormente impressos nas páginas dos livros; e também pouco ou nada sabem sobre os problemas metodológicos envolvidos em tais processos de transcrição, organização e edição - algo que particularmente me preocupa.

Em 1988, uma equipe de investigadores, conhecida como Equipa Pessoa, chefiada por Ivo Castro, iniciou estudos para um amplo projeto de edições críticas da obra de Fernando Pessoa, atuando diretamente no espaço da Biblioteca Nacional de Portugal, local onde se encontra o famoso espólio do escritor. A tarefa a que este grupo de trabalho passou a se dedicar reflete a necessidade - que já fora sentida por outros investigadores e que ainda há - de se colocar em questão criticamente as publicações dos escritos de Pessoa, tanto as obras já editadas (e mesmo aquelas editadas em vida), quanto as obras inéditas que ainda surgirão a partir do corpo fragmentado do espólio; o que se impõe é a necessidade de retornar aos textos originais, de retornar aos manuscritos e datiloscritos, e de buscar, nestes, aquilo que Pessoa de fato escreveu e que poderá, sob um trabalho de edição que deve sempre ser pensado criticamente e explicitado enquanto mediação, tornar-se a obra que chegará aos leitores.

Em continuidade ao trabalho e às linhas metodológicas da Equipa Pessoa - esta que, por sua vez, dava seguimento, embora em linhas próprias, a iniciativas paralelas de importantes investigadores da obra de Fernando Pessoa (muitos dos quais seguem em atividade, como a já citada Teresa Rita Lopes) -, edições críticas de éditos e inéditos continuam a ser publicadas pela editora Imprensa Nacional - Casa da Moeda, ao lado de muitas outras publicações dentro e fora de Portugal, como as conhecidas edições da Assírio \& Alvim, explicitando que há muito ainda a descobrir e a redescobir no espólio de Pessoa.

Entre os investigadores da obra pessoana, o nome do professor e pesquisador colombiano Jerónimo Pizarro destaca-se na última década com participação ativa nos estudos sobre o escritor português e com importantes realizações editoriais, sobretudo no campo da crítica textual. Pizarro foi responsável pelas edições críticas, entre outras, do Livro do Desasocego ${ }^{i}$, de A Educação do Stoico e dos textos reunidos em Escritos sobre Génio e Loucura, também organizou volumes de ensaios e artigos como Fernando Pessoa: O Guardador de Papéis e A Arca de Pessoa e recentemente trabalha em novos projetos editoriais da Ática em torno da obra pessoana. Outro importante projeto em que Pizarro esteve diretamente envolvido foi o de catalogação e digitalização da biblioteca pessoal de Fernando Pessoa - acervo que se encontra guardado na Casa Fernando Pessoa, em Lisboa. Atualmente vinculado à Universidad de los Andes, na Colômbia, Jerônimo Pizarro passou a última década ligado a Lisboa a fim de estudar a obra de Fernando Pessoa (primeiramente à distância e, posteriormente, mergulhado no espólio), o que resultou nos diversos projetos de crítica textual - alguns dos quais acima citados - no âmbito dos escritos éditos e inéditos pessoanos.

Meu primeiro contato com Jerônimo Pizarro deu-se através da leitura das instigantes páginas introdutórias de sua recente edição do Livro do Desasocego, já nas primeiras semanas de minha estadia em Lisboa em função de minha pesquisa 
desenvolvida na capital portuguesa desde Março de 2011; pouco tempo depois, tive um primeiro contato pessoal com o investigador colombiano (ainda que à distância protocolar) ao assistir sua comunicação no âmbito do Colóquio Internacional NietzschePessoa-Freud, também em Lisboa, em Maio deste ano. Cada vez mais envolvido, em minhas investigações, com as questões éticas e metodológicas que atravessam os processos editoriais de Fernando Pessoa, iniciei contato direto com Pizarro - o que, a esta altura, só pode ser efetuado através da internet, uma vez o pesquisador já havia retornado à Colombia. De uma frutífera troca de emails, surgiu a idéia de concretizar nosso diálogo na forma de uma entrevista. Escrevi as questões e as enviei a Pizarro; de suas respostas, produzi novas indagações para novas respostas do entrevistado.

A entrevista ou, talvez, a conversa epistolar que se segue, realizada entre o final de Julho e o início de Agosto de 2011, busca levantar, com a contribuição de Pizarro, algumas importantes questões acerca do trabalho de edição dos escritos de Pessoa, revelando, sobretudo, que a obra de Pessoa, sendo sempre o fruto de um trabalho "coletivo" que envolve leitura crítica dos originais (e das edições já publicadas) e decisões editoriais, deve estar, inevitavelmente, em constante revisão e transformação o que, longe de impedir a apreciação literária da obra, exige (ou deve exigir) uma postura crítica diante de qualquer publicação.

\section{2) Entrevista}

Certamente, Fernando Pessoa não foi um escritor completamente desconhecido em vida - e, apesar de não sobreviver do ofício da literatura, participava ativamente da vida literária lisboeta e portuguesa; no entanto, é certo que, do volume de escritos que hoje conhecemos sob sua autoria, aquilo que chegou ao público de sua época é uma ínfima parte. $E$ é igualmente certo que somente ao longo dos anos posteriores à sua morte Pessoa tornou-se uma das figuras icônicas da literatura portuguesa - talvez o grande poeta lusitano ao lado de Camões, como é continuamente reconhecido mesmo por aqueles que nunca leram quaisquer versos de sua autoria, dentro e fora de Portugal. A fama de Pessoa é, portanto, póstuma; e tal fama se alimenta, em boa parte, justamente do caráter paradoxalmente vivo de uma obra que não cessa de ser escrita e reescrita através das constantes (e, aparentemente, infinitas) publicações de éditos e inéditos do autor, afora os inúmeros estudos críticos derivados de seus escritos, dentro e fora do âmbito académico - estudos que o abordam sob múltiplas perspectivas, não apenas literárias. Com a recente entrada da obra de Fernando Pessoa em domínio público, o volume de edições e publicações tende a se ampliar e, diante da possibilidade de crescente difusão, parece necessária uma postura prudente: como o senhor escreve, ao lado de Steffen Dix, na introdução ao volume de ensaios $A$ Arca de Pessoa: "[a] nova liberdade editorial é também um desafio pela simples razão de que Fernando Pessoa não deixou para a posteridade uma ou várias 'obras', mas sim milhares de fragmentos, planos, esboços ou projectos” (Dix; Pizarro, 2007, 
p.18). A questão inicial que aqui proponho é: o que o levou a enfrentar tal desafio? Em outras palavras, o que o levou de uma leitura crítica das obras de Fernando Pessoa ao trabalho de edição crítica do autor? Ou o interesse pela crítica textual o levou a Pessoa como objeto exemplar de trabalho?

Também acho que Pessoa não foi um escritor completamente desconhecido em vida e que, proporcionalmente, ficaram muitíssimos mais escritos inéditos do que publicados nas suas arcas; daí essa grande torrente de publicações póstumas que está longe de se esgotar. Ora, não todos os textos de Pessoa foram igualmente conhecidos: Associações secretas causou uma grande comoção política, mas não Ultimatum, pois a revista Portugal Futurista foi apreendida pela polícia, que desativou, por assim dizer, a "bomba"; Autopsychographia apareceu na revista Presença, mas outros textos em publicações periódicas de pouca tiragem ou de curta vida, tais como as revistas Teatro e A Renascença, que, em palavras de Pessoa, "morreu à nascença" (Pessoa, 2009, p.99).

Pergunta-me se foi o interesse pela crítica textual que me levou a Pessoa como objeto exemplar de trabalho. Acho que foi Pessoa que me levou à crítica textual, ou melhor, que foi Pessoa que me levou a perceber a insuficiência da crítica literária quando os "alicerces" filológicos são fracos ou nulos. Pessoa era um desafio a muitos níveis, dos quais saliento os dois principais, a meu ver: a nível crítico, porque depois de Jorge de Sena, de Octavio Paz e de Eduardo Lourenço poucas figuras de relevo deixaram grandes textos sobre a obra pessoana (hoje destacaria, limitando-me a autores portugueses, a António Mega Ferreira e a José Barreto); e a nível textual, porque praticamente todos os problemas da crítica textual tradicional e da crítica textual moderna, como, por exemplo, a atribuição de um texto a um determinado autor ou o tratamento das variantes de autor em textos inéditos ou publicados, são problemas que a obra pessoana coloca e atualiza.

\section{Como foi a sua aproximação acadêmica com Fernando Pessoa? E como esta aproximação desenvolveu-se no trabalho mais intensivo da crítica textual?}

A minha aproximação acadêmica com Fernando Pessoa começou na Universidade Nova de Lisboa, mas teve o seu momento de revelacão quando já morava nos EUA e fiz uma viagem, no Verão de 2003, a Lisboa para trabalhar no espólio pessoano. Durante o Mestrado na Nova nunca passei pelo espólio, porque essa não era uma passagem que os professores incentivassem. Conhecer o referido espólio, conhecer o "Pessoa por Conhecer", foi decisivo: fez-me perceber a necessidade da filologia, fez-me descobrir o trabalho da Equipa Pessoa, fez-me escrever um segundo doutoramento (anterior ao de Harvard), de índole crítica e editorial, orientado por Manuel Gusmão e Ivo Castro. Um espólio, tal como o espólio pessoano, pode ser uma autêntica epifania. Essa epifania 
teve, entre outros resultados, uma participacão ativa na Equipa Pessoa, a digitalização da Biblioteca Particular de Fernando Pessoa, e actualmente a coordenação da Nova Série da Editora Ática, assim como da colecção de Ensaística pessoana, também da Ática.

A tarefa das edições críticas é, em certa medida, expor, ao menos parcialmente, o próprio trabalho de edição; evidenciar que há, entre o material original e o texto publicado, um processo, que envolve escolhas - sobretudo, técnicas, a partir de critérios críticos e estéticos. Na introdução a Fernando Pessoa: Guardador de Papéis, o senhor afirma, a certa altura, "a notável construção coletiva de Pessoa como autor póstumo” (Pizarro, 2009, p.11). Dentro de tal perspectiva, poderíamos afirmar que esse caráter "coletivo" se funda como necessária mediação à nossa leitura dos escritos pessoanos (sobretudo os inéditos em vida), de modo que somente podemos lê-lo - conscientes disso ou não, alertados quanto a isso ou não como um autor póstumo e construído; autor fantasmático evocado por um conjunto de investigadores e editores, trabalhando solitariamente ou não, que, pouco a pouco desenham e redesenham essa obra inacabada e aparentemente infinita. Consciente de que quase toda obra literária ou, mais amplamente, editorial, atravessa a mediação de terceiros - pois o texto raramente sai dos originais de trabalho diretamente para o produto editorial (embora os blogs apontem para esta crescente possibilidade) -, gostaria que comentasse o caráter de construção coletiva e, portanto, mediada, das edições das obras póstumas de Pessoa e que se colocasse com relação à posição de neutralidade técnica/científica assumida nas edições crítico-genéticas - posição de neutralidade que pressupõe justamente a evidenciação da mediação e não o seu disfarce ou apagamento, como ocorre recorrentemente em diversas edições das obras pessoanas.

Para mim uma boa edição crítica é, em simultâneo, uma edição transparente, que revela as decisões e conjecturas do editor, e uma edição que dedica muito tempo e espaço à pesquisa e à crítica de fontes (veja-se, a este respeito, uma edição redimensionada através desse tipo de crítica e de pesquisa: Provérbios Portugueses, 2010).

Sobre a questão da mediação editorial... Sim. Pessoa é e será cada vez mais um "autor póstumo e construído". Esse é o seu fado, e também o nosso, enquanto leitores, críticos e editores de uma obra que ficou "por armar", para citar Julio Cortázar. Ora, esta condição obriga a relativizar um dos ideais implícitos de muitas teorias da edição: o da "neutralidade técnica/científica" que deveria assumir o editor. Não porque o editor não deva procurar uma alta objectividade, mas porque no caso concreto de editar Fernando Pessoa é quase conveniente e inevitável que o editor seja um agente ativo e autónomo, que faça novas propostas de edição, e essa "neutralidade" não pode ser 
absoluta. Explico melhor. Estando, como estamos, ainda muito longe de um "cânone textual" mais ou menos estabelecido das obras de Fernando Pessoa; estando, como estamos, ainda muito longe de ter transcrito a totalidade do seu legado literário; estando, como estamos, ainda muito longe de uma datação crítica da maior parte dos seus escritos; e não dispondo, como não dispomos, de indicações do autor referentes à organização da maior parte das suas obras; nestas condições, perante estas incertezas, o mais urgente é um apelo ao rigor e à prudência, mas a um rigor e uma prudência que não inibam completamente o editor, pois o editor de Fernando Pessoa é um editor que deve "trair" o autor constantemente, quer optando por títulos que este não concebeu, por exemplo, quer organizando um conjunto textual de uma forma que este não chegou a deixar bem definida. A neutralidade absoluta não é possível a partir do momento em que temos que agir para além do autor, em que devemos, conscientemente, tomar decisões mesmo sem gozar de todos os elementos necessários ou todas as informações desejáveis para o efeito.

Penso agora na palavra "testemunho" e tomo o conceito de testemunha como o sobrevivente que media ou representa o relato ou a voz daquele que não pode testemunhar pois não está mais presente (aquele que foi ao fundo e não voltou, remetendo-me aqui, à distância, à obra de Primo Levi). Com esta palavra em mente, questiono: até que ponto pode o leitor conhecer a obra de Fernando Pessoa? Noutras palavras, somente podemos conhecer cada obra de Pessoa segundo (o testemunho indireto de) este ou aquele editor, que afinal lidaria com uma obra sempre "por conhecer" a partir de outros testemunhos, estes materiais/indiciais, dos documentos parciais de uma criação inacabada?

Mas Pessoa está nos seus testemunhos, isto é, em cada papel que legou e que contém um testemunho escrito. Não temos o seu testemunho oral, mas ficou o escrito, e se os seus testemunhos autógrafos forem bem editados, sempre é possível uma aproximação muito fiável à sua "criação inacabada", aos seus projectos, aos seus planos, às suas ideias. E acho altamente cativante a inacabada aproximação a essa criação aberta; é quase simbólica e evoca a espiral dos mitos.

Diante de toda obra póstuma e inacabada (deixada sob a forma de manuscritos, datiloscritos e anotações avulsas, constituindo um conjunto imperfeito de textos muitas vezes ainda afastados do processo de uma possível edição), há sempre o risco de se colocar frente a textos efetivamente reconstruídos por terceiros como se diante de criações finalizadas e publicadas sob a autoridade e autorização do próprio escritor. Pessoa guardou grande parte (a maior parte, creio) daquilo que, ao longo dos anos, escreveu - uma imensidão de textos espalhados em cerca de 30.000 papéis avulsos ou encadernados. No entanto, como era de se esperar, 
guardou de forma não sistemática - assim como acontece com qualquer coleção particular e imersa no cotidiano da vida corrente. Frente ao conjunto vasto de papéis manuscritos e datiloscritos, em diversas épocas e sobre distintos materiais, que constituem aquilo que podemos chamar - mesmo que sempre com algum desconforto - a obra de Fernando Pessoa, somos lançados, inevitavelmente, a diversos problemas. Embora, em se tratando de uma produção literária (de um já canonizado poeta), não se possa abrir mão dos problemas estéticos que sua escrita provoca, numa tomada geral poderíamos colocar as dificuldades de se lidar com o vasto conjunto de escritos no âmbito ético. Em outras palavras, posso afirmar, mesmo à distância, que editar Fernando Pessoa é tarefa árdua que exige enfrentar dilemas não apenas estéticos ou críticos, mas, antes de tudo, éticos - é tarefa que exige tomar posturas. Dentro de tal perspectiva, qual a postura que deve tomar um editor de textos pessoanos? Do seu ponto de vista, há uma única postura viável ou “justa”? Há qualquer impostura condenável?

Não sei se vejo dilemas éticos, propriamente. A minha posição é a de que todo o papel que Pessoa guardou, porque continha um texto, deve ser transcrito. Por isso tenho defendido a publicação dos Cadernos e de muitos outros suportes que contêm textos que se podem considerar mais ou menos privados ou históricos. A meu ver, mais do que dilemas éticos, existe a necessidade de cumprir umas regras editoriais mínimas: a transparência, a publicação "do que ficou" e não "do que poderia ter sido", o reconhecimento de omissões e decifrações incertas, etc. Penso que é menos ético, se o pensarmos nesses termos, a publicação pouco honesta de um texto do que o facto de o publicar.

Justamente considero que defender ou pôr em discussão se um texto deve ou não ser publicado ou como deve ser publicado ou, ainda, qualquer necessidade de cumprir regras atravessa uma reflexão ética que se impõe sobre o próprio trabalho do editor. Nesse sentido, gostaria que comentasse a presença e a importância dos prefácios e introduções às edições pessoanas e a necessidade de o editor (ou organizador) se auto-evidenciar (e evidenciar suas decisões e posturas de trabalho - o que pode se desdobrar em artigos periféricos ao trabalho de edição, como o seu Sobre a Exumação Sistemática da Arca, entre outros).

Todo o material que "envolve" o texto (prefácio, posfácio, notas, cabeçalhos, etc.) é também uma oportunidade para o editor não cair numa certa tentação de invisibilidade. Como editor, é bom não ser invasivo, não tentar entrar numa espécie de guerra de protagonismo com o autor (é o pecado de muitas edições eruditas), mas também é conveniente, e necessário no caso de Pessoa, uma declaração editorial, isto é, uma explicação de como o organizador fez com que um texto inexistente (Argumentos para Filmes, por exemplo ${ }^{\mathrm{ii}}$ ) "ganhasse" existência. Pessoa agradeceu um dia a Gaspar 
Simões, porque este, com o seu estudo, o tratou como "realidade espiritual" e o reconheceu como "nação independente" (carta de 26-VI-1929). Cada edição de um conjunto textual pessoano cria uma nova entidade e é importantíssimo que o agente da edição explique a génese da mesma.

Há um gesto forte implícito na opção por editar o Livro do Desasocego com a grafia peculiar de Pessoa, sobretudo quando a “obra” em questão já é reconhecida pela grafia costumeira (e ortograficamente "correta") de Livro do Desassossego. Um dos problemas centrais ao se lidar com os manuscritos pessoanos é lidar com as particularidades de escrita do autor (seus arcaísmos e estrangeirismos, sobretudo), assim como com os erros (que podem ser sistemáticos ou casuais) - isso sem falar na grande dificuldade que é decifrar alguns de seus manuscritos. Em minha pouca experiência com os originais de Fernando Pessoa, consultados no acervo digital da BNP nos últimos meses, confesso que cheguei a me assustar com as escolhas de alguns organizadores e editores de Pessoa frente tanto à questão da grafia, quanto ao modo de lidar com as lacunas, com as variáveis alternativas ou com trechos de difícil leitura; o trabalho das edições críticas buscam, a princípio, evitar ao menos que as decisões editoriais sejam tomadas à revelia do leitor. Gostaria que comentasse a respeito de tais problemas - partindo de suas opções de trabalho frente à questão da correção ou atualização ortográfica.

Esse "gesto forte implícito na opção por editar o Livro do Desasocego com a grafia peculiar de Pessoa", já estava anunciado na opção por editar A Educação do Stoico sem o $E$ antes do $S$. Esta foi uma maneira de vincar a diferença entre a versão comercial e a versão crítica do Livro, e um gesto de coerência com o próprio projeto da Edição Crítica de Fernando Pessoa. Deste projecto, aliás, faz parte João Dionísio, quem, com Joaquim Mendes, deixou um magnífico artigo que gostaria de evocar - e que pode ser lido como um manifesto de princípios muito liberais - sobre a questão ortográfica: intitula-se $A$ ortografia segundo Pessoa e critérios editoriais, e foi publicado na Revista da Biblioteca Nacional ${ }^{i i i}$. Ali Dionísio e Mendes referem essas "particularidades de escrita do autor" e comentam algumas das suas opções. Qual a minha posição frente à atualização ortográfica? Que esta é necessária e até inevitável, mas que não deve ser a única opção de um editor, porque também é importante não apagar a história da língua e poder ler o português em toda a sua multiplicidade. Quando leio Pessoa num português atualizado sinto que estou a ler um heterónimo, isto é, o texto que uma figura fictícia passou para novos moldes, seguindo regras que o autor não conheceu. Esta opção é perfeitamente viável e legítima, mas rasura muitas particularidades e não contribui para a familiarização com a ortografia pessoana. De fato, algumas decifrações erradas devem-se a um desconhecimento da ortografia do autor. No entanto, como leitor, reconheço que a questão ortográfica não é uma das mais relevantes. 
Em conversa com o professor Steffen Dix, na qual discutíamos as diferentes possibilidades de organização das obras póstumas de Pessoa nas diversas publicações disponíveis e imagináveis - publicações realizadas sob critérios frequentemente díspares e, por vezes, incompatíveis de organização -, levantou-se a questão da (im)possibilidade de edição definitiva das obras de Fernando Pessoa (ao menos das inéditas em vida); Dix sugeriu que, diante das obras póstumas (como o $L$. do $D$.), tal tarefa poderia ser irrealizável, pelo menos no que diz respeito à organização dos textos em obras publicáveis sob o suporte canônico do livro; diante do problema, sugeriu que uma plataforma digital poderia ser um caminho viável - justamente, creio, pelo aspecto móvel e, afinal, justamente por isso, nunca efetivamente definitivo. Há alguns meses, em palestra no Rio de Janeiro, Richard Zenith, ao responder uma questão relativa ao seu critério de organização do $L$. $d o$ $D$., levantou como possibilidade teórica a organização do $L$. do $D$. em folhas avulsas, sem ordem pré-estabelecida - mimetizando, portanto, em parte, a estrutura do próprio espólio pessoano. Correntemente, cogita-se a possibilidade de solução do problema através da publicação em fac-símile dos documentos originais, eventualmente acompanhados de transcrições - opção que jogaria ao leitor a tarefa de investigar: o leitor posto na posição de um investigador em segundo grau (ainda distante dos originais, mas já apto a questionar as eventuais transcrições e edições). As edições crítico-genéticas não se põem muito à distância disto, visto que o volume crítico acompanhado do aparato genético - a chamada Série Maior das edições da Imprensa Nacional - Casa da Moeda - serve assumidamente não a uma leitura "recreativa", mas a uma leitura técnica, crítica, investigativa. No artigo Sobre a exumação sistemática da arca, o senhor defende o imperativo de se "fixar todo o espólio de Pessoa", o que se daria através da "transcrição de cada texto do espólio, edição a edição", percorrendo todo o corpo de documentos "de modo a não deixar lacunas" iv . Reconhecendo que tal trabalho de fixação total é um passo anterior à possibilidade de qualquer edição definitiva, gostaria que comentasse o duplo desafio de construir os textos a partir dos alicerces tortuosos e por vezes arruinados dos documentos e de, posteriormente, organizá-los como obras editoriais - especulando volumes, títulos, temas, etc.

Também acredito na impossibilidade da edição definitiva das obras de Fernando Pessoa - e acho que é um erro falar em "Obras Completas" no caso deste autor - e na necessidade de uma plataforma digital, mas móvel, para o editar. A solução não passa por esse ato comercial e de certa forma claudicante de publicar Pessoa (ou o Livro do Desasocego) em folhas avulsas, nem pelo fac-símile (sem transcrição), que seria um simulacro duvidoso dos autógrafos pessoanos, feito para as estantes de uma biblioteca; basta pensar nas edições volumosas de cadernos de Valéry ou de Joyce... A meu ver, é necessário o estabelecimento textual de todos os escritos que Pessoa guardou nas suas arcas bem como a sua publicação, on-line ou em papel, sob rigorosos critérios. Sempre 
será mais valioso um site dedicado a Caeiro ${ }^{\mathrm{v}}$, por exemplo, com vários índices e modos de navegação, do que um simples repositório de imagens sem descrição material nem datação crítica e sem ligação a outros documentos que iluminem uma determinada produção.

Complementando a questão anterior, coloco em questão a postura da crítica literária: o que deve fazer o crítico literário diante de uma obra inacabada e ainda longe de ter sido estabelecida ou fixada? Deve arriscar a cair no erro e especular sobre textos e escritos porventura equivocadamente transcritos, incorretamente ou, quem sabe, maldosamente organizados, ou erroneamente atribuídos a um ou outro dos heterónimos e outros nomes pessoanos ou mesmo ao próprio Pessoa (penso nos textos traduzidos ou transcritos por Pessoa de outros autores e erradamente atribuídos a ele ou a um dos heterônimos); ou deve a crítica silenciar e aguardar e, assim, cautelosamente resguardar-se aos textos publicados em vida? Noutra perspectiva, que tipo de integração pode ou deve haver entre a crítica e o trabalho investigativo-editorial?

Acho que da mesma maneira que Pessoa requer um editor ativo, também requer um crítico ativo. Quase todos os biógrafos e críticos de Pessoa acham que Pessoa fundou a Empreza Ibis em 1907 e não em 1909 (por um erro de leitura inicial - a data de uma carta - que se filtrou no decurso do tempo e que só veio a ser corrigido meio século mais tarde), mas é melhor escrever do que "silenciar e aguardar" e "resguardar-se aos textos publicados em vida". Ora, este exemplo também sugere que a integração entre a crítica literária e a crítica textual, entre a interpretação e a edição, é verdadeiramente fulcral e decisiva. Eu não concebo escrever sobre Fernando Pessoa sem voltar às fontes com uma assiduidade mínima. E considero que é preciso mudar de atitude e começarmos a adoptar um princípio de dúvida não apenas no plano crítico (ler com suspeita a carta sobre a gênese dos heterônimos, por exemplo), mas também no plano textual (ler com suspeita o Livro do Desasocego, entre muitas outras obras, incluindo a Ode Triumphal, publicada em vida, mas com uma ligeira imperfeição, como revelou Gianluca Miraglia num artigo publicado em Estudos Italianos em Portugal, 2, 2007).

O trabalho sobre os documentos de Fernando Pessoa - grande parte já arquivados na BNP ou na Casa Fernando Pessoa (embora tantos ainda se mantenham dispersos) - envolve escavação, recolha, seleção, levantamento histórico-biográfico, decifração manuscriptológica e, enfim, um profundo trabalho de especulação. A vida de Pessoa foi, até certo ponto, enigmática, pois, por um lado, "pobre" de biografia e, por outro, viva em (auto)mitificação e (auto)mistificação - portanto, prato cheio para conjecturas e ficcionalizações. $\mathbf{E}$ podemos afirmar que a morte prematura de Pessoa e a guarda, por parte do autor, da maior parte de seus 
escritos em sua arca - ao longo de três décadas -, sendo tais escritos inacabados e precários, alimentam, inevitavelmente, o ímpeto especulativo por parte de leitores, críticos e investigadores, no âmbito da literatura ou mesmo fora dela, afinal, Pessoa não foi apenas o poeta consagrado postumamente; escreveu prosas literárias, textos dramáticos e produziu muitos outros escritos filosóficos, sociológicos, políticos, etc., sob a autoria de muitos outros nomes para além dos consagrados heterónimos Álvaro de Campos, Alberto Caeiro e Ricardo Reis. Há certamente um encanto na especulação; e, ao mesmo tempo, esta é necessária quando se busca enfrentar as inevitáveis lacunas presentes em uma vastidão de obras póstumas e fragmentárias; e creio que deve ser muito satisfatório partir de uma especulação dedutiva/imaginativa e alcançar a comprovação material lembro-me da sua comentada "alegria crítica" no artigo Por que uma nova edição do Livro do Desasocego ${ }^{v i}$, ao alcançar uma datação para um conjunto de documentos pessoanos. No entanto, vejo certo perigo no que poderia chamar de voracidade especulativa. Muitos trabalhos que tenho lido ou escutado em palestras e comunicações são movidos ou tomados pelo desejo de explicar ou revelar a obra pessoana em sua "verdade" e, por vezes, parecem não ter o pudor ou temer o risco de reinventar a vida de Pessoa (e sua personalidade) ou inventar a obra que nunca existiu (talvez, a partir de algumas das muitas listas de projetos nunca realizados em vida por Pessoa). Gostaria de questionar-lhe sobre os limites da especulação: até que ponto se pode ou se deve especular diante de uma obra como a de Fernando Pessoa? E, noutra perspectiva, até que ponto interessa traçar uma relação entre a vida e a obra do autor e, desta relação, buscar revelar as origens criativas de obras de Fernando Pessoa? E penso aqui penso, com destaque, nos trabalhos realizados nos últimos anos na biblioteca pessoal do autor na Casa Fernando Pessoa: a análise das anotações de Pessoa nas capas, contra-capas, sobrecapas e margens das páginas dos livros, assim como das marcações em que o autor destacava passagens e trechos das obras lidas têm suscitado um grande número de produtivas reflexões que, em grande parte, buscam estabelecer relações diretas ou indiretas entre leituras realizadas por Pessoa e textos criados pelo autor, além de diversas conjecturas biográficas.

Concordo, existe um "certo perigo" no que se poderia chamar de "voracidade especulativa". A meu ver, a filologia impõe limites à especulação e daí a necessidade de reivindicarmos a filologia, que perdeu tanto prestígio na França e nos Estados Unidos, por um entendimento muito restrito do que comporta a filologia e as disciplinas que a compõem, tais como a paleografia ou a bibliografia material, por exemplo. Aliás, uma edição crítica é o resultado de muitos trabalhos de índole filológica e é, como disse Ivo Castro (1995), "o produto mais completo da crítica textual"vii.

Ora, "traçar uma relação entre a vida e a obra do autor" é para mim uma finalidade interessantíssima. No caso de Pessoa é possível continuar a escrever os esboços de uma 
grande biografia intelectual, porque temos um volume de marginalia enorme, porque no futuro vamos ter uma cronologia muito precisa da produção pessoana e porque, se os factos da vida de Pessoa continuarem a ser escassos, os dados sobre os seus escritos e as suas leituras continuarão em aumento. Eu sonho com uma cronologia que reconstrua dia a dia, ou quase, a vida de Pessoa, indicando menos o que fez (porque é cada vez mais irrealizável) e mais o que escreveu e leu (porque é cada vez mais factível). Leitura e criação são "vasos comunicantes", como diria André Breton.

Sobretudo por ser em grande parte um autor póstumo, a obra de pessoa (aquela que pode ser recuperada de seu espólio) está de fato inevitavelmente entrelaçada com a sua vida, ainda mais porque seus escritos se acumulam fragmentariamente por décadas desta vida. $O$ senhor fala no sonho de uma reconstrução cronológica de uma vida literária, por assim dizer, de Pessoa (em torno da criação e da leitura) - inevitavelmente imersa na vida cotidiana ou biográfica do autor. A partir disso, eu pergunto: pensa que é o caráter lacunar dessas duas vidas entrelaçadas (literária e biográfica) o que causa o ímpeto de se investir constantemente na evocação de Pessoa? Acredita que parte do encanto de se ler pessoa (em vida e obra) é o caráter misterioso e enigmático que se extrai das falhas e incertezas que constroem a figura e a literatura de Pessoa? (Caráter misterioso e enigmático que, de fato, parece alimentado pelo próprio pessoa em seu jogo de personalidades jogo que frequientemente extravasa o espaço literário/ficcional).

É muito provável que o "caráter lacunar" da vida-obra de Pessoa estimule o seu mito, até porque é de espaços vazios ou enigmáticos que depende um mito para se prolongar e estender. A constelação-Pessoa, esse mito gigante, está cheia de mistérios não isentos de encanto. Lembro uma das regras de vida de Pessoa: "Try to charm by what is in your silence" (cota 28-43); e lembro que o autor da Mensagem se definiu como um "sebastianista racional" e que escreveu que o ano de 1888, o do seu nascimento, era um ano decisivo na historia profética de Portugal...

Julho/Agosto de 2011.

\footnotetext{
' No Brasil, 0 Livro do Desassossego, com esta grafia, foi publicado com edição de Teresa Sobral Cunha pela Editora Unicamp em dois volumes (1996), e, como Livro do Desassossego, em edições de Richard Zenith, pela editora Companhia das Letras (1999).

ii Argumentos para filmes é um livro lançado em Julho deste ano reunindo escritos relacionados ao cinema de autoria de Fernando Pessoa; editado por Patricio Ferrari e Claudia Fischer para a coleção Nova Série, da editora Ática.

iii Revista da Biblioteca Nacional, série 2, volume 3, número 3, pp. 183-198

${ }^{\text {iv }} \mathrm{O}$ artigo foi publicado on-line em Portal Pessoa, site que já não está mais disponível; alguns artigos do portal, dentre os quais, Sobre a exumação sistemática da arca, de Jerônimo Pizarro, foram posteriormente 
disponibilizados em http://blog.umfernandopessoa.com/2010/01/artigos-recuperados-do-portalpessoa.html.

${ }^{\mathrm{v}} \mathrm{Cf}$. http://purl.pt/1000/1/alberto-caeiro/index.html - site realizado como parte do projeto Manuscritos de Pessoa em linha, que disponibiliza on-line os originais pessoanos das poesias de Alberto Caeiro guardados na Biblioteca Nacional de Portugal.

${ }^{\mathrm{vi}}$ Texto ainda inédito cedido pelo autor.

${ }^{v i i}$ Filologia in: Biblos - Enciclopédia Verbo das Literaturas de Língua Portuguesa. Lisboa: Editorial Verbo, 2006.

\section{Referências Bibliográficas}

CASTRO, Ivo. Editar Pessoa. Lisboa: INCM, 1990.

DIX, Steffen; PIZARRO, Jerônimo (Org.). A arca de Pessoa : novos ensaios. Lisboa: ICS - Imprensa de Ciências Sociais, 2007.

PESSOA, Fernando. Livro do Desasocego. Tomos I e II. Ed. Jerônimo Pizarro. Lisboa: INCM, 2010.

Sensacionismo e outros ismos. Ed. Jerônimo Pizarro. Lisboa: INCM, 2009.

A Educação do Stoico. Edição Jerônimo Pizarro. Lisboa: INCM, 2007.

- Escritos sobre génio e loucura. 2 volumes. Ed. Jerónimo Pizarro. Lisboa : INCM, 2006.

PIZARRO, Jerônimo (Org). Fernando Pessoa : o guardador de papéis. Alfragide : Texto, 2009.

Fernando Pessoa : entre génio e loucura. Lisboa : INCM, 2007.

. Sobre a exumação sistemática da arca in: Portal Pessoa, 2006.

Por que uma nova edição do Livro do Desasocego. Inédito (ver nota vi). 